\title{
Three-dimensional Evaluation of Facial Harmony in Orthodontic Patients with Vertical Growth Pattern
}

\author{
Rim M. Fathalla*, Abbadi A. El Kadi, Mohamed A. Nadim \\ Department of Orthodontics, Faculty of Dentistry at Suez Canal University, Egypt
}

\begin{abstract}
Aim: To three-dimensionally evaluate the facial harmony in orthodontic patients with vertical growth pattern. Materials and Methods: Cone-beam computed tomography (CT) scans were obtained in 10 normal occlusion adults ( 4 men, 6 women) with vertical growth pattern, and reconstructed into 3dimensional (3D) models by using a 3D image software. 3D position of 12 hard tissue landmarks, 3 midlines and 9 pairs of bilateral landmarks, were identified in $3 \mathrm{D}$ coordination system, and their right and left differences were calculated and analyzed. Results: The right and left difference values derived from the study indicated a degree of facial asymmetry in the vertical growers. The lateral ramal inclination was the most asymmetric value. Conclusions: A degree of facial asymmetry exists in the vertical growers. The lateral ramal inclination is a significant parameter in the assessment of facial asymmetry in the vertical growers. Facial asymmetry tends to increase according to the lower and lateral positioning of the landmarks in the face. There is a tendency towards left-side dominance.
\end{abstract}

Keywords: Cone-beam computed tomography, facial asymmetry

\section{Introduction}

Facial asymmetry is one of the characteristic traits used to assess facial beauty and attractiveness $^{(1)}$. The human face is bilaterally symmetrical, divided into right and left halves. However, it was found that there is always a degree of deviation from this perfect symmetry. That's why a perfectly symmetrical face doesn't always correlate to a beautiful face $^{(2)}$. In light of this, it must be emphasized that facial asymmetry is a common finding $(3-$ 5). Many radiographic imaging techniques have been used to assess the facial asym- metry such as the submentovertex technique $^{(6,7)}$, the poster anterior cephalograms $^{(8,9)}$ and the panoramic radiography ${ }^{(10,11)}$. However, these two-dimensional imaging methods have many shortcomings; magnification, distortion and projection errors. Variation in skull rotation during submentovertex projection affects both linear and angular measurements significantly ${ }^{(12,13)}$. Also, projection errors influence the angular measurements in postero-anterior cephalometry(14). According to several electronic databases, vertical measurements taken from conventional or digital panoramic im 
ages are still not true representations of the real objects they correspond to due to magnification errors ${ }^{(15)}$. With the recent advances in the $3 \mathrm{D}$ radiographic modalities, facial asymmetry could be evaluated with greater accuracy and reproducibility ${ }^{(16-18)}$. Data of previous studies revealed great variability of the two-dimensional radiographic methods from the gold standard, while they found that the three-dimensional evaluation was much more precise ${ }^{(19)}$. Furthermore, three-dimensional computed tomography was used to assess the topography of facial asymmetry and it was found to be a practical method of evaluating the morphology of facial asymmetry $(20,21)$. Studies showed that three-dimensional soft tissue analysis provided information about vertical skeletal parameters, which allowed assessment of vertical craniofacial morphology(22). The patient's growth pattern influences the skeletal, dental, soft tissue components of the face, as well as the facial profile. Since, these components are contributing to facial asymmetry, assessment of facial asymmetry in patients with different vertical growth patterns is an essential part of diagnosis. The purpose of the present study was to use the cone-beam computed tomography in the evaluation of facial asymmetry in patients with vertical growth pattern.

\section{Materials and Methods}

The subjects of this study were selected from patients seeking orthodontic treatment at the Orthodontic Clinic, Faculty of Dentistry, Suez Canal University. The selected sample included 10 patients, 6 females (mean age 20.5 years) and 4 males (mean age 20.9 years), with the following criteria (Age range from 18 years to 25 years, full complement of permanent teeth (excluding third molars), no previous orthodontic/ orthopedic/orthognathic surgical treatment, no history of trauma and no obvious gross facial asymmetry). For each selected patient, a lateral cephalogram to determine the type of growth was taken using cephalometric machine Orthophox under the following conditions $90 \mathrm{KV}, 12 \mathrm{~mA}, \mathrm{CCD}$ CEPH 23,00 x $0.65 \mathrm{~cm}$. During $x$-ray projection, the patient is standing in an upright position with a relaxed facial expression and the Frankfurt Horizontal plane is parallel to the floor. Cone beam computed tomography was used to assess the facial asymmetry. The computed tomography scans were obtained using SCANORA cone beam CT imaging device under the following conditions $90 \mathrm{KV}, 10 \mathrm{~mA}$ [Fig 2 (a) and (b)], voxel size $0.5 \mathrm{~mm} \times 0.3$ $\mathrm{mm}$, field of view (FOV) (H x D) $240 \times 165 \mathrm{~mm}$. The image data produced are in digital imaging and communication in medicine (DICOM) format. The OnDemand3D software version is used to reconstruct the axial images into a 3D model. During 3D scanning, the patient is seated in an upright position and the midsagittal plane is perpendicular to the floor. The cephalometric radiographs of the patients were traced and analyzed to determine the type of patient's growth. The following cephalometric angular measurements were recorded: Sum of posterior angles (Bjork angle) $=$ SNAr + SArGo + ArGoMe, Y-axis, Facial axis angle, Gonial angle, Upper gonial angle, and Lower gonial angle. The type of the growth pattern for each patient was determined based on the following cephalometric readings ${ }^{(23)}$. To evaluate the facial asymmetry, the following 3D landmarks were identified on the 3D CT images by using the OnDemand3DApp. 1.0.9.2469. The parameters used to assess facial asymmetry included $^{(24)}$ : 1. Maxillary Height: First molar to Fran- 
Table 1: Parameters used to assess the patient's growth pattern

\begin{tabular}{|l|c|c|c|}
\hline & \multicolumn{3}{|c|}{ Methods for Predicting Growth Direction } \\
\hline Parameter & Range & Variation & Type of Growth \\
\hline Sum of Posterior angles (Bjork) & $396^{\circ} \pm 6$ & $\begin{array}{c}<390 \\
>402\end{array}$ & $\begin{array}{c}\text { Horizontal } \\
\text { Vertical }\end{array}$ \\
\hline Y-axis & $61^{\circ} \pm 6$ & $\begin{array}{c}<55 \\
>67\end{array}$ & $\begin{array}{c}\text { Horizontal } \\
\text { Vertical }\end{array}$ \\
\hline Facial axis angle (Ricketts) & $87^{\circ} \pm 7$ & $\begin{array}{c}<80 \\
>94\end{array}$ & $\begin{array}{c}\text { Horizontal } \\
\text { Vertical }\end{array}$ \\
\hline Gonial angle & $124^{\circ} \pm 5$ & $\begin{array}{c}>129 \\
<119\end{array}$ & $\begin{array}{c}\text { Vertical } \\
\text { Horizontal }\end{array}$ \\
\hline Upper Gonial angle & $52^{\circ} \pm 3$ & $>55$ & Horizontal \\
\hline Lower Gonial angle & $70^{\circ} \pm 5$ & $>75$ & Vertical \\
\hline
\end{tabular}

kfurt Horizontal (Po-Or-Po)-distance between the Frankfurt Horizontal (FH) plane and the occlusal fossa of the maxillary first molar (in $\mathrm{mm}$ ) 2 . Mandibular Height: Canine to mandibular plane (Ag-Me-Ag), distance from the canine cuspal tip perpendicular to the mandibular plane (in $\mathrm{mm}$ ). 3.Ramus Length: Condylion superior-Gonion inferior-distance between the highest point of the condyle and the lowest point of the gonion area (in mm). 4.Mandibular Body Length: Menton-Gonion posterior, distance between menton and the most posterior point of the gonion area (in $\mathrm{mm})$. 5.Frontal Ramal Inclination: Condylion lateral-Gonion lateral to midsagittal reference plane (Op-Cg-ANS)-angle formed by the $\mathrm{FH}$ plane and the posterior border of the ramus (in degrees). 6.Lateral Ramal Inclination: Condylion
posterior-Gonion posterior to $\mathrm{FH}$ (Po-Or- Po), angle formed by the $\mathrm{FH}$ plane and the posterior border of the ramus (in degrees). The right and left sides of the face for every patient were compared to determine the degree of facial asymmetry. All the data were tabulated and analyzed using the Statistical Package of Social Science Software program, version 21 (SPSS).

\section{Results}

The means and standard deviations of each parameter of facial asymmetry and of the right and left differences of the landmarks in every patient are presented in table 3 and figures ( 1 and 2 ). The lateral ramal inclination

Table 2: Parameters used to assess the facial asymmetry

\begin{tabular}{|c|c|c|}
\hline Landmark & Abbreviation & Description \\
\hline 1. Crista galli & $\mathrm{Cg}$ & Most superior point of crista galli of ethmoid bone. \\
\hline 2. Opisthion & Op & Most post. point on post. margin of foramen magnum. \\
\hline 3. Porion & Po & Highest point on roof of external auditory meatus. \\
\hline 4. Orbitale & Or & Deepest point on infraorbital margin \\
\hline 5. Condylion superius & Cd sup & Most superior point of condyle head \\
\hline 6. Condylion lateralis & Cd lat & Most lateral point of condyle head \\
\hline 7. Condylion posterius & Cd post & Most posterior point of condyle head \\
\hline 8. Gonion lateralis & Go lat & Most lateral point of gonion area \\
\hline 9. Gonion posterius & Go post & Most posterior point of gonion area \\
\hline 10. Gonion inferius & Go inf & Most inferior point of gonion area \\
\hline 11. Antegonion & $\mathrm{Ag}$ & Deepest point of antegonial notch of mandible \\
\hline 12. Menton & Me & Most inferior point on mandibular symphysis \\
\hline
\end{tabular}


was found to be the most asymmetric value, followed by the ramus length. The mandibular height was the least asymmetric value. The left side measurements of the face were higher than the right-side measurements re garding the maxillary height, the mandibular body length, the frontal ramal inclination and the lateral ramal inclination. The rightside measurements were higher for the mandibular height and the ramus length.

Table 3: Description of each parameter for the group of Vertical Growers

\begin{tabular}{|c|c|c|c|c|c|c|c|c|c|c|}
\hline & \multicolumn{10}{|c|}{ Vertical growers } \\
\hline & \multicolumn{3}{|c|}{ Range } & \multirow{2}{*}{$\begin{array}{c}\text { Mean } \\
46.0\end{array}$} & \multirow{2}{*}{$\begin{array}{l} \pm \\
\pm\end{array}$} & \multirow{2}{*}{$\begin{array}{l}\text { SD } \\
3.4\end{array}$} & \multirow{2}{*}{$\begin{array}{c}\text { Median } \\
46.2\end{array}$} & \multicolumn{3}{|c|}{ IQR } \\
\hline RT Maxillary Height & 42.6 & - & 53.9 & & & & & 42.7 & - & 46.4 \\
\hline LT Maxillary Height & 44.3 & 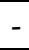 & 52.7 & 47.2 & \pm & 2.8 & 46.2 & 45.1 & - & 48.9 \\
\hline RT Mandibular Height & 35.4 & - & 45.9 & 40.1 & \pm & 3.6 & 38.8 & 37.5 & - & 42.7 \\
\hline LT Mandibular Height & 35.4 & - & 46.4 & 39.5 & \pm & 4.2 & 38.2 & 35.7 & - & 43.4 \\
\hline RT Ramus Length & 50.7 & - & 78.7 & 61.3 & \pm & 9.5 & 59.1 & 52.8 & - & 69.8 \\
\hline LT Ramus Length & 48.5 & - & 72.1 & 58.6 & \pm & 7.6 & 55.4 & 54.9 & - & 64.6 \\
\hline RT Mandibular body length & 104.0 & - & 134.4 & 119.5 & \pm & 9.4 & 117.3 & 114.2 & - & 123.8 \\
\hline LT Mandibular body length & 107.7 & - & 137.1 & 119.7 & \pm & 9.5 & 117.4 & 112.5 & - & 124.4 \\
\hline RT Frontal Ramal Inclination & 67.5 & - & 86.0 & 79.1 & \pm & 5.1 & 80.5 & 76.5 & - & 82.5 \\
\hline LT Frontal Ramal Inclination & 70.0 & - & 86.5 & 81.0 & \pm & 5.3 & 81.5 & 80.0 & - & 85.5 \\
\hline RT Lateral Ramal inclination & 72.0 & 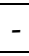 & 85.5 & 77.5 & \pm & 4.7 & 76.8 & 73.5 & - & 81.0 \\
\hline LT Lateral Ramal inclination & 77.5 & - & 88.5 & 83.0 & \pm & 3.4 & 82.0 & 81.0 & - & 86.0 \\
\hline Maxillary Height Differences & 0.4 & - & 7.4 & 2.2 & \pm & 2.0 & 1.8 & 0.9 & - & 2.5 \\
\hline Mandibular Height Difference & 0.0 & - & 2.1 & 1.0 & \pm & 0.9 & 0.6 & 0.3 & - & 2.1 \\
\hline Ramus Length Differences & 0.3 & - & 6.6 & 3.5 & \pm & 2.0 & 4.0 & 2.9 & - & 4.3 \\
\hline Mandibular body length Diff. & 0.1 & - & 4.7 & 2.1 & \pm & 1.7 & 2.2 & 0.3 & - & 3.7 \\
\hline Frontal Ramal Inclination Diff. & 0.0 & - & 9.0 & 2.9 & \pm & 2.7 & 2.3 & 1.0 & - & 3.5 \\
\hline Lateral Ramal inclination Diff. & 0.0 & - & 9.5 & 5.5 & \pm & 3.4 & 6.3 & 3.0 & - & 8.5 \\
\hline
\end{tabular}

$\mathrm{SD}=$ standard deviation, $\mathrm{IQR}=$ interquartile range (Range from $25^{\text {th }}-75^{\text {th }}$ percentiles)

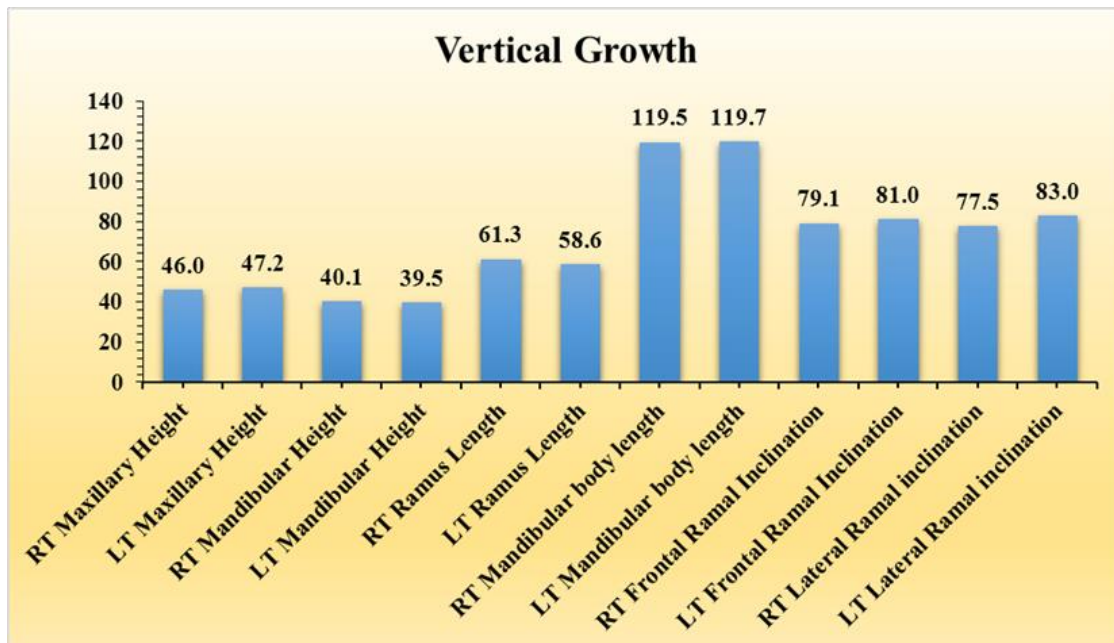

Figure 1: Histogram showing the measured values for each parameter on each side for the vertical grower. 


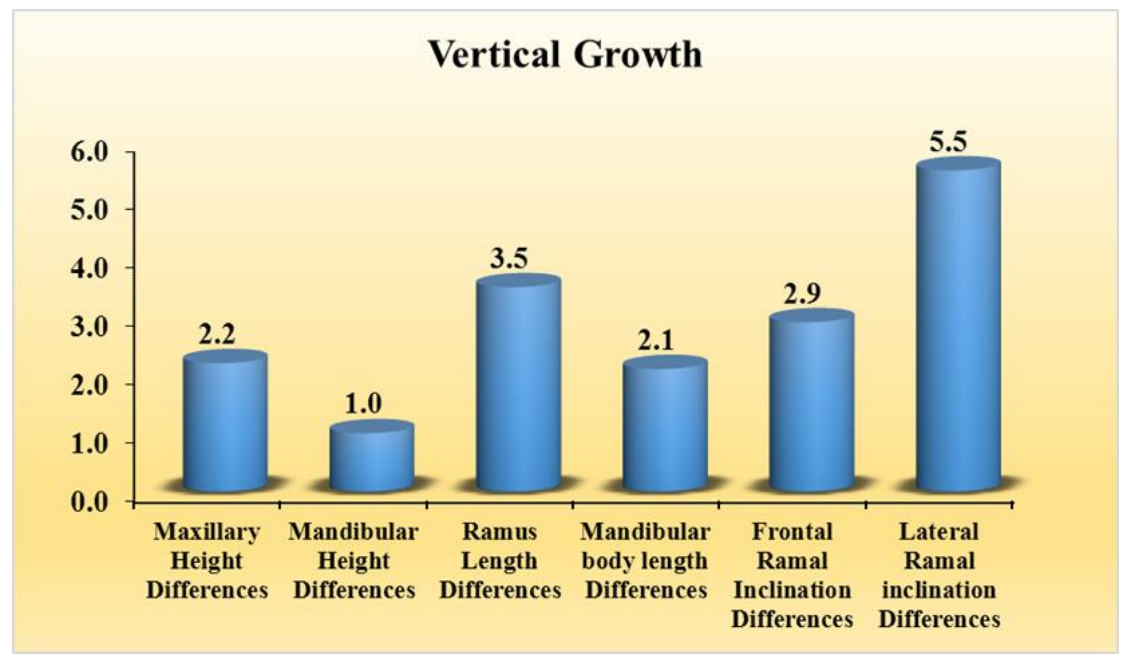

Figure 2: Histogram showing the means differences of facial asymmetry parameters for the vertical growers.

\section{Discussion}

Many previous studies have evaluated the facial asymmetry using 2D and 3D imaging techniques. However, there weren't enough studies, assessing the facial asymmetry in patients with vertical growth pattern. In the present study, cone beam computed tomography was used to assess the facial asymmetry in patients with vertical growth pattern. The introduction of 3D imaging methods, such as CBCT , has reduced the errors of magnification and distortion as well as the projection errors of the 2D imaging techniques. This was confirmed by previous studies ${ }^{(18,22,25,26)}$. In the present study, four linear measurements in millimeters and two angular measurements in degrees were used to measure the facial asymmetry. These measurements are the same used by Dharmesh et al $^{(17)}$ for the assessment of facial asymmetry. According to the means and standard deviations of the right and left difference of facial asymmetry parameters of the subjects, it was found that a degree of facial asymmetry exists in the vertical growers. This result agreed with other studies(3-5,27). Lateral ramal inclination was found to be the most asymmetric value, followed by the ramus length in the vertical growers' group. This suggests that asymmetry increases with the lower positioning and the lateral positioning of landmarks. The current results agreed with other studies $(2,4,28,29)$. This finding also was confirmed by Hwang et $\mathrm{al}^{(30)}$, who demonstrated that the degree of facial asymmetry tended to increase with the lower and lateral positioning of landmarks. However, the present study disagreed with the study carried by Frakas and Cheung(31), who found that the most asymmetric part of the face (69.2\%) was the upper third. This may be attributed to the fact that these authors carried out their study on normal Caucasian children and used anthropometrics to evaluate the facial asymmetry. Also, the current results are found to be in disagreement with Ferrario et al(32). The latter author showed that there was a certain degree of soft tissue facial asymmetry both in individuals and in global populations and that this was especially evident in the middle (tragus) and not only in the lower (gonion) thirds of 
the face. These findings may be due to the different ethnic group used in the study. Moreover, Ercan et al(33), showed that the most asymmetric part of the face in both sexes was the middle third of the face. In the previous study, the facial landmark data were collected from two-dimensional digital images of 321 young healthy subjects. This could explain why these findings were different from the results of the present study. The present results disagreed with some of the findings of Dhermash et $\mathrm{al}^{(17)}$, who revealed that the mandibular body length was the most asymmetric value obtained by using the conventional radiographic images . This might be attributed to the use of additional two-dimensional radiographic method in the latter study and to the different ethnic group. Laterality of asymmetries is defined as differences between the dimensions of the left and right halves of the face. The current results confirmed that there was a leftside dominance. These results were in accordance with some studies $(28,34,35)$. However, the present results disagreed with others studies $(4,17,31,36)$, that found a slight tendency toward right-side dominance. In the study carried by Peck et al(36) ,they used a different technique in the assessment of the facial asymmetry, which was the postero-anterior cephalometry and a different ethnic group.

\section{Conclusions}

The study concludes that: i) A degree of facial asymmetry was detected in the vertical growers. ii) The lateral ramal inclination was found to be a significant parameter in the assessment of facial asymmetry in patients with vertical growth pattern. lii) This study confirmed the previous studies findings that facial asymmetry increased with the lower and lateral positioning of landmarks. Iv) The left side measurements of the face were found to be greater than the right side.

\section{References}

1. Todd SA, Hammond P, Hutton T, Cochrane S, Cunningham S. Perceptions of facial aesthetics in two and three dimensions. Eur J Orthod. 2005 ;27(4):363-9.

2. Swaddle JP, Cuthill IC. Asymmetry and human facial attractiveness: symmetry may not always be beautiful. Proc Biol Sci. 1995; 22;261(1360):111-6.

3. Farrera A, Villanueva M, Quinto-Sánchez M, González-José R. The relationship between facial shape asymmetry and attractiveness in Mexican students. Am J Hum Biol. 2015; 27(3):387-96.

4. Rajpara Y, Shyagali TR, Trivedi K, Kambalyal P, Sha T, Jain V. Evaluation of facial asymmetry in esthetically pleasing faces. J Orthod Res 2014; 2:79-84.

5. Ferrario VF, Sforza C, Ciusa V, Dellavia C, Tartaglia GM. The effect of sex and age on facial asymmetry in healthy subjects: a cross-sectional study from adolescence to mid-adulthood. J Oral Maxillofac Surg. 2001;59(4):382-8.

6. Uysal T, Malkoc S. Submentovertex cephalometric norms in Turkish adults. Am J Orthod Dentofacial Orthop. 2005 ;128(6):724-30.

7. Maglione M, Costantinides F. Localization of Basicranium Midline by Submentovertex Projection for the Evaluation of Condylar Asymmetry. Int J Dent. 2012; 2012:285693.

8. Trpkova B, Prasad NG, Lam EW, Raboud D, Glover KE, Major PW. Assessment of facial asymmetries from posteroanterior cephalograms: validity of reference lines. Am J Orthod Dentofacial Orthop. 2003 ;123(5):512-20.

9. Rajpara Y, Shyagali TR, Trivedi K, Kambalyal P, Sha T, Jain V. Evaluation of facial asymmetry in esthetically pleasing faces. J Orthod Res 2014; 2(2):79-84. 
10. Habets LL, Bezuur JN, Naeiji M, Hansson TL. The Orthopantomogram, an aid in diagnosis of temporomandibular joint problems. II. The vertical symmetry. J Oral Rehabil. 1988 ;15(5):465-71.

11. Sağlam AA, Sanli G. Condylar asymmetry measurements in patients with temporomandibular disorders. J Contemp Dent Pract.2004;5(3):59-65.

12. Cheng AC, Lew KK, Bhole S. Head positioning and projection errors in submentovertex radiographic analysis. Singapore Dent J. 1997; 22:13-17.

13. Williamson PC, Major PW, Nebbe B, Glover KE. Landmark identification error in submentovertex cephalometrics. A computerized method for determining the condylar long axis.Oral Surg Oral Med Oral Pathol Oral Radiol Endod. 1998; 86(3):360-9.

14. Ahlqvist J, Eliasson S, Welander U. The effect of projection errors on angular measurements in cephalometry. Eur $J$ Orthod. 1988;10(4):353-61.

15. Van Elslande DC, Russett SJ, Major PW, Flores-Mir C. Mandibular asymmetry diagnosis with panoramic imaging.Am $J$ Orthod Dentofacial Orthop. 2008; 134(2):183-92.

16. Cavalcanti M, Rocha S, Vannier MW. Craniofacial measurements based on 3D-CT volume rendering: implications for clinical applications. Dentomaxillofac Radiol 2004; 33:170-176.

17. Dharmesh HS, Alle RS, Suma T. Diagnosis of Facial Asymmetry Using Conventional PA Cephalometric Analysis and a Maxillofacial 3-Dimensional CT Analysis: A Comparative Study. Orthodontic CYBER J. 2012.

18. Kook MS, Jung S, Park HJ, et al. A comparison study of different facial soft tissue analysis methods. J Craniomaxillofac Surg. 2014;42(5):648-56.

19. Adams GL, Gansky SA, Miller AJ, Harrell WE Jr, Hatcher DC. Comparison between traditional 2-dimensional cephalometry and a 3-dimensional approach on human dry skulls. Am J Orthod Dentofacial Orthop. 2004 126(4):397-409.

20. Grummons D, Ricketts RM. Frontal cephalometrics: practical applications, part 2. World J Orthod. 2004 ;5(2):99-119.

21. Katsumata A, Fujishita M, Maeda M, Ariji Y, Ariji E, Langlais RP. 3D-CT evaluation of facial asymmetry. Oral Surg Oral Med Oral Pathol Oral Radiol Endod 2005; 99(2):212-20.

22. Kochel J, Meyer-Marcotty P, Kochel M, Schneck S, Stellzig-Eisenhauer A. 3D soft tissue analysis--part 2: vertical parameters. J Orofac Orthop. 2010 ;71(3):207-20.

23. Zribi A, Faure J. Contribution of three dimensional cephalometry in the study of determining morphological parameters for facial esthetics. Orthod Fr. 2014 ;85(1):51-8.

24. Bell A, Lo TW, Brown D, et al. Three-dimensional assessment of facial appearance following surgical repair of unilateral cleft lip and palate. Cleft Palate Craniofac J. $2014 ; 51(4): 462-71$.

25. Cavalcanti M, Rocha S, Vannier MW. Craniofacial measurements based on 3D-CT volume rendering: implications for clinical applications. Dentomaxillofac Radiol 2004; 33(3):170-6.

26. Schwenzer-Zimmerer K, Chaitidis D, Berg-Boerner I, et al. Quantitative 3D soft tissue analysis of symmetry prior to and after unilateral cleft lip repair compared with non-cleft persons (performed in Cambodia). J Craniomaxillofac Surg. 2008; 36(8): 431-8.

27. Letzer GM, Kronman JH. A Posteroanterior Cephalometric Evaluation of Craniofacial Asymmetry. Angle Orthod 1967; 37(3): 205-11.

28. Haraguchi S, Takada K, Yasuda Y. Facial asymmetry in subjects with skeletal Class III deformity. Angle Orthod. 2002; 72(1):28-35.

29. Lee MS, Chung DH, Lee JW, Cha KS. Assessing soft-tissue characteristics of facial asymmetry with photographs. Am J 
Orthod Dentofacial Orthop. 2010 ;138(1):23-31.

30. Hwang HS, Yuan D, Jeong KH, Uhm GS, Cho JH, Yoon SJ. Three-dimensional soft tissue analysis for the evaluation of facial asymmetry in normal occlusion individuals. Korean J Orthod .2012; 42(2):56-63.

31. Farkas LG, Cheung $G$. Facial asymmetry in healthy North American caucasians. Angle Orthod.1981;51(1):70-7.

32. Ferrario VF, Sforza C, Poggio CE, Tartaglia G. Distance from symmetry: a three-dimensional evaluation of facial asymmetry. J Oral Maxillofac Surg. 1994; 52(11):1126-32.
33. Ercan I, Ozdemir ST, Etoz A, et al. Facial asymmetry in young healthy subjects evaluated by statistical shape analysis. J Anat. 2008;213(6):663-9.

34. Vig PS, Hewitt AB. Asymmetry of the human facial skeleton. Angle Orthod. 1975; 45(2):125-9.

35. Fong JH, Wu HT, Huang MC, et al. Analysis of facial skeletal characteristics in patients with chin deviation. J Chin Med Assoc. 2010 ;73(1):29-34.

36. Peck S, Peck L, Kataja M. Skeletal asymmetry in esthetically pleasing faces. Angle Orthod. $1991 ; 61(1): 43-8$ 